\title{
Issues Arising from the Creation of Special Economic Zone in Southern Thailand: A Scoping Step of Rapid Health Impact Assessment
}

\author{
Suvapak Benjatanawat ${ }^{1}$, Sang-arun Isaramalai ${ }^{2}$, Dudsadee Muenhor ${ }^{3}$, Pongthep Sutheravut ${ }^{4}$ \\ ${ }^{1}$ Ph.D. Student, ${ }^{2}$ Assistant Professor, Faculty of Nursing, ${ }^{3}$ Assistant Professor, Faculty of Environmental \\ Management, ${ }^{4}$ Assistant Professor, Faculty of Pharmaceutical Sciences, Health Impact Assessment Research \\ Center, Public Policy Institute, Prince of Songkla University, Hat Yai, Songkhla, Thailand
}

\begin{abstract}
Background: Special Economic Zone (SEZ) policy of Thai government aimed to promote the economy in bordered provinces. Its establishment may cause concerns and impacts on communities. This article explores those issues arising from SEZ establishment in Southern Thailand.
\end{abstract}

Method: The scoping step of rapid health impact assessment process was applied using documentary research combined with qualitative descriptive approaches, including focus group discussions, interviews, and brainstorming. Data were collected from seventy participants, comprising government officials, local government officials, community leaders, public health volunteers, members of local organizations, and local residents. Content analysis was used to analyze the data.

Conclusion: The most important issues were found in four aspects-economic, social, environmental, and health. The economic aspect involved higher income and more employment opportunities, while for the environmental aspect, the issues were related to waste management and water pollution. The social issues comprised the build-up of traffic and the influx of migrant workers. The health issues were emerging/reemerging infectious diseases, particularly from migrant workers and the insufficiency of health services. As a result, a rapid health impact assessment should be carried out based on these issues. It should be taken into consideration by local officials responsible for developing and regulating the SEZ.

Keywords: Scoping, rapid health impact assessment, special economic zone.

\section{Introduction}

Special economic zones (SEZ) is an economic development policy adopted in many countries ${ }^{(1)}$. Its advantages are mainly economic, such as increasing foreign direct investment and export value. Furthermore, SEZs help generate employment and increase income for the localcommunity ${ }^{(2,3)}$. However, SEZs also have negative impacts, such as the losses of agricultural or

\footnotetext{
Corresponding Author:

Sang-arun Isaramalai

Faculty of Nursing, Prince of Songkla University, Hat

Yai, Songkhla, Thailand

e-mail: isangarun@hotmail.com
}

forest land and living space, causing residents to become landless, jobless, or income loss ${ }^{(4-6)}$. Other problems concern pollution from industrialization ${ }^{(2)}$ and infectious diseases from immigrants ${ }^{(7,8)}$.

Health impact assessment (HIA) is a procedural tool for assessing health impacts, widely used in many countries, including Thailand ${ }^{(9)}$. Rapid HIA is a type of HIA that requires fewer resources and time, or there is little time available for decision making ${ }^{(10,11)}$. HIA consists of six main steps: screening, scoping, assessing, reviewing, reporting, and monitoring and evaluation ${ }^{(12)}$. In the scoping step, the key issues/topics relating to health concerns are identified by questioning the community residents or stakeholders about policies, projects, or activities $^{(13)}$. The results from this step provide the 
boundaries for the HIA, including 1) key topics/issues to consider, 2) populations and stakeholders affected, 3) geographical area covered, 4) timescale, and 5) tools or method for acquiring data ${ }^{(13)}$.

In Thailand, SEZs is a government policy, which aims to promote trade and investment, improve quality of life, and develop outlying provinces. Its implementation consists of creating industrial estates, facilities, and transportation networks, and logistical systems. These activities impact the health of local community residents. Thus, HIAs are indispensable for rapidly assessing health impacts by focusing on community concerns. The objective of this study was to conduct the scoping step for a rapid HIA to explore and identify community concerns or issues arising from the creation of the SEZ by using Songkhla SEZ in Southern Thailand as a case study.

Study Area: Songkhla SEZ was established since it is a highly developed area bordering Malaysia. Its area covers four sub-districts of Sadao district in Songkhla province, i.e., Sadao, Padang Besar, Samnak Kham, and Sumnak Taeo. The important goal of Songkhla SEZ can be summarizedas 'export processing industries and multimodal transport' ${ }^{(14)}$.

\section{Materials and Method}

This action research was conducted between January and July 2018. Documentary research and qualitative approaches were used for data collection, including focus-group discussions, face-to-face interviews and brainstorming techniques. Content analysis was implemented for all data.

\section{Documentary research: Twenty-one} documentaries related to SEZ impacts were reviewed. These impacts were collected using data extraction sheet and can be grouped in four aspects-economic, social, environmental, and health.

Focus-group discussions: Four focus group discussions were conducted in the four sub-districts. The participants comprised twelve community leaders, sixteen community residents, fourteen public health volunteers, two civil society officers, and six local government staff. They were asked with open-ended questions, i.e., 'What do you expect from Songkhla SEZ?', 'What benefits will you or your community gain from Songkhla SEZ?', and 'What are the main economic/social/environmental/health problems in your community?' Data was analyzed.

Face-to-face interviews: Face-to-face interviews were performed with six informants comprising three government officers, one academic, one local government staff, and one member of a non-government organization. The key informants were interviewed to gather information about the situation and impacts that may result from the SEZ using the same open-ended questions used for the focus-group discussions. Data were analyzed.

Brainstorming Techniques: A brainstorming session was conducted with 24 participants comprising four government officers, ten local government staff, six community leaders, two health volunteers, and two members of local organizations. Sub-group meetings and World Café method were employed to allow participants to voice, share, and discuss their opinions related to SEZ impacts. The issues were identified and prioritized by applying the Problem Prioritization Method. Data from brainstorming were analyzed.

Data Credibility: Methodological and data triangulation were used to ensure that the findings of the study provided useful results from different perspectives. Methodological triangulation was performed by using different method for gathering data. Data triangulation was conducted by using various data sources.

Ethical Considerations: This study was approved by the Health Human Research Ethics Committee of Health System Management Institute, Prince of Songkla University (EC 012/60).

\section{Results and Discussion}

SEZs are policies with potential socioeconomic, social, and environmental effects impinging on the health status of local people ${ }^{(15)}$. The issues arising from Songkhla SEZ were identified and prioritized within the scoping step of rapid HIA in four aspects: economic, social, environmental, and health.

Economic Aspect: Songkhla SEZ establishment benefits the community economically as it increases community income and provides employment for local inhabitants.

Community Residents' Income: The community income should be increasing, as indicated in the following statements: 
"It will stimulate the local economy. Local dwellers should have more income." (Local government staff)

"More outsiders are coming, so the business is likely to be better" (Community resident)

Conversely, some opinions were stated that others, such as investors, would gain more income, as shown by the following:

"Investors will receive most benefit. We do not get any benefit." (Community leader)

Community residents around SEZ areas generally expect to earn higher incomes. Mendoza found that cities in China with preferential policies for SEZs had higher income growth than other cities ${ }^{(16)}$. While the growth in average workers' remuneration in municipalities with SEZs was greater than that of cities without an $\mathrm{SEZ}^{(3)}$.

Community residents' employment: The community residents expected employment by the companies established in Songkhla SEZ. As one informant said:

"People in this area and nearby will be employed, get paid, and have a better living." (Local government staff)

However, a different opinion was found, as the statement below:

"The investors and their capital have not brought any benefit to the communities." (Local organization member)

SEZ has the potential to increase the local employment rate ${ }^{(17)}$.However, SEZs in India required people who had special skills and expertise because most investments in SEZs were aimed at modern techniques and technologies ${ }^{(5)}$. While, a large amount of employment was generated for low-skilled workers in some SEZs ${ }^{(18)}$.

Social Aspect: Various issues were revealed, including the traffic problem, an influx of migrant workers, and illegal drug use. However, the community prioritized road traffic and an influx of migrant workers from Songkhla SEZ establishment.

Increase in road traffic: Heavy traffic congestion is now a problem in the Songkhla SEZ area, especially on the main road to immigration checkpoints, as can be seen from the statements below:
"There are a lot of articulated lorries waiting to pass through to Malaysia." (Local government staff)

"There are often traffic jams, especially in the late afternoon, and this is our problem." (Community leader)

Traffic is an important issue, especially in the area near to the border checkpoints with Malaysia. This problem is expected to increase and become worse for the communities. It is consistent with the International Institute for Trade and Development who found that community residents and entrepreneurs in the first five SEZs in Thailand were most concerned about traffic ${ }^{(2)}$. Similarly, traffic congestion always follows when industrialization and urbanization occur in a city ${ }^{(19)}$.

Influx of migrant workers: The influx of migrant workers was concerned since many outside workers could affect community safety and increase robberies, burglaries, and other crimes. As one said:

"When there are outsiders, there will be robbers, burglars, and crimes. Then, people in the community will not live peacefully anymore." (Community leader)

It is consistent with other studies that a massive influx of migrant workers may cause problems, such as an increase in crime, fights and civil disturbances, and drug trafficking ${ }^{(2,7,8)}$. Local government staff was much concerned about the safety of people and the protection of their property from migrant workers. Migrant workers also contributed to rapid population growth and an increase in the number of vehicles resulting in a higher volume of traffic and more road accidents ${ }^{(19)}$.

Environmental aspect: The environmental concerns consisted of water pollution, air pollution, and waste and waste management. The issues 'waste and waste management' and 'water quality' were prioritized.

Waste and waste management: Waste and its management were the main issues in Songkhla SEZ area because there is only one sanitary landfill site with a fee charge in the area, as the following statements:

"We have a lot of garbage but we don't have a place for disposal. We have to take our trash to disposal site and pay 50 Stang per kilogram or about 0.0014 USD per kilogram. That is over three hundred thousand baht (over nine thousand USD) a month. " (Local government staff) 
"There will be waste from factories. How can it be managed? Where's the dump site? How can it be treated? Who pays?" (Academic)

Waste and waste management issues were concerned because there is only one sanitary landfill site located in Sadao Municipality ${ }^{(20)}$. This disposal site has been operated since 2000 and is expected to be available for the next 2-3 years ${ }^{(21)}$. Samnak Kham Sub-district municipality was particularly concerned about waste because many restaurants, bars, and other entertainment venues are in the area.

Water quality: The water quality of U-taphao canal, a natural reservoir in the area, was another prioritized issue, as the statements below:

"This area is the water source of U-taphao canal. If we have factories that affect the environment, it will affect downstream." (Local government staff)

"If the wastewater treatment system of factories is not sound, it will affect people. Initially, the water quality in U-taphao canal was not good. (Academic)

SEZs with industrial estates and other development projects may deteriorate water quality. In urban areas of Malaysia, residential, industrial, commercial, and recreational land-use activities have significant impacts on water quality ${ }^{(22)}$. These development activities are a major source of water pollution and also affect groundwater ${ }^{(23)}$. Besides, Nissaisuk found that the health of local residents around the eastern seaboard industrial development in Rayong province was affected by foul odors from industrial waste and chemicals leaking into the water supply(24).

Health aspect: Two issues were concerned, diseases brought in by migrant workers and the sufficiency, comprehensiveness, and readiness of the health service system.

Physical health: Local residents were concerned about diseases carried by migrant workers with either new infectious diseases or diseases that have been previously controlled in Thailand, such as malaria, tuberculosis, leprosy, and meningococcal disease, as indicated by the following:

"We worried about hemorrhagic fever. Sometimes diseases are brought into the area and spread here." (Local government staff)
"Many of them come, and we do not know what diseases they bring along." (Health volunteer)

Infectious diseases carried by migrant workers were a matter of concern. Tongchaisuwan et al. ${ }^{(8)}$ found that foreign workers who worked in Mae $\mathrm{Ai}$ district in Chiang Mai carried contagious diseases, such as tuberculosis and measles, and diarrhea, which could be transmitted to local people. The conditions they lived were overcrowded, and there were problems with the cleanliness and sanitation, which represented health risks. However, Thai people now have better attitudes towards migrant workers and understand that communicable diseases, such as tuberculosis, may be carried by migrant workers and Thais ${ }^{(25)}$.

\section{Local public health service systems}

The sufficiency, comprehensiveness, and readiness of the local public health service systems were issues to the communities, as indicated by the following:

"Hospital here cannot now provide sufficient health services, the treatment and care are not efficient because it is a small hospital." (Community leader)

"The services are not satisfactory, as is generally known. Many people have had bad experiences." (Community resident)

Songkhla SEZ establishment has caused an increase in population, mainly an increase of migrant workers, which has resulted in an increasing load on public health services and utilities in the municipality. Therefore, community residents thought that migrant workers should be legally registered and carry health insurance to obtain regular medical check-ups and health services from local health providers. This finding agrees with the study by Yang et al. ${ }^{(26)}$, which found that the same medical treatment policies should apply to immigrants and non-immigrants alike.

\section{Conclusion}

The issues of concern identified by residents and other stakeholders in four sub-districts were found in four aspects: economic, social, environmental, and health. These issues were determinants with a causal relationship affecting health. They should set a future framework of rapid health impact assessment and be considered by local officials responsible for developing and regulating the SEZ. 
Acknowledgement: This article is a part of a thesis financially supported by the National Research Council of Thailand for 2018.

Conflict of interest: The authors declare that there is no conflict of interest.

\section{References}

1. UNIDO Country office in Vietnam. Economic Zones in the Asean. Viet Nam: United Nations Industrial Development Organization; 2015.

2. International Institute for Trade and Development. Guidelines and Measures for the Development of Special Economic Zones in the Border Areas of Thailand. Nonthaburi, Thailand: Sahamitr Printing and Publishing; 2015.

3. Wang J. The economic impact of Special Economic Zones: Evidence from Chinese municipalities. J Dev Econ. 2013;101:133-47.

4. Bhaskar. Impact of Special Economic Zone on Indian Economy. Int J Manag Stud. 2018;5(2):6470.

5. More JB. Impact of Special Economic Zone in India. Int J Commer Bus Manag IJCBM. 2015;4(1):8739.

6. Parwez S, Sen V. Special Economic Zone, Land Acquisition, and Impact on Rural India. Emerg Econ Stud. 2016;2(2):223-239.

7. Muenratch $\mathrm{P}$, Pardthaisong L. The impactsof migrant workers in agricultural sector:a case study of Cambodian workers in longan orchardareain Lamphun province. Veridian E-Journal Silpakorn Univ Humanit Soc Sci Arts. 2017;10(2):558-71.

8. Tongchaisuwan C, Juntarawijit Y, Lueng-a-papong S. Health Impact of Migrant Labour on People in Mae Ai District, Chiang Mai Province. Thail J Health Promot Environ Health. 2010;33(4):60-72.

9. Mattig T, Cantoreggi N, Simos J, Favre Kruit C, Christie DPTH. HIA in Switzerland: strategies for achieving Health in All Policies. Health Promot Int. 2017;32(1):149-56.

10. Harris A. Rapid Health Impact Assessment: A Guide to Research. United Kingdom: New Deal for Communities Nottingham.

11. National Research Council. Improving Health in the United States: The Role of Health Impact Assessment. Washington (DC): National Academies Press (US); 2011.
12. National Center for Environmental Health. CDC - Healthy Places-Health impact assessment. 2017 [cited 2019 Sep 1]. Available from: https://www. cdc.gov/healthyplaces/hia.htm

13. Metcalfe O, Higgins $C$, Lavin T. Health Impact Assessment Guidance. Institute of Public Health in Ireland; 2009.

14. Office of the Board of Investment. A Guide to Investment in the Special Economic Development Zones. Thailand: Thailand Board of Investment; 2018.

15. Bert F, Scaioli G, Gualano MR, Siliquini R. How can we bring public health in all policies? Strategies for healthy societies. J Public Health Res. 2015;4(1):43-6.

16. Valerio Mendoza OM. Preferential policies and income inequality: Evidence from Special Economic Zones and Open Cities in China. China Econ Rev. 2016;40:228-40.

17. Kumari B, Tayyab M, Shahfahad, Rahman A. Role of Special Economic Zone (SEZs) in Creation of Employment, Investment and Export in India. Int $\mathrm{J}$ Manag Stud. 2018;V(3(9)):15-22.

18. Niraj AD. Impact of Special Economic Zones on Indian Economy. Int J Soc Sci Humanit Res. 2016;4(4):565-73.

19. Tuong PV. Development of Special Economic Zones, Industrial Estates, Ports, Metropolis and Alternative Roads in the Greater Ho Chi Minh City Area. In: Ishida M, editor. Intra-and Inter-City Connectivity in the Mekong Region. Bangkok, Thailand: Bangkok Research Center; 2011.

20. Regional Environmental Office 16 (Songkhla). Environmental Situation Report 2018 (Songkhla, Satun, Pattani, Yala, and Narathiwat). Office of the Permanent Secretary, Ministry of Natural Resources and Environment; 2019.

21. Industrial Estate Authority of Thailand. EIA Report: Industrial Estate Project in Songkhla Special Economic Zone (full report). Industrial Estate Authority of Thailand; 2018.

22. Camara M, Jamil NR, Abdullah AFB. Impact of land uses on water quality in Malaysia: a review. Ecol Process. 2019;8(1).

23. Kumar P, Dasgupta R, Johnson BA, Saraswat C, Basu M, Kefi M, et al. Effect of Land Use Changes on Water Quality in an Ephemeral Coastal Plain: Khambhat City, Gujarat, India. Water. 
2019;11(4):724.

24. Nissaisuk N. The Impact of Eastern Seaboard Industrial Development, Rayong: A Case Study of Mab Yangporn Community, Pluak Daeng District, Rayong Province [Special Problem in Public and Private Management, M.P.A.]. Burapha University; 2013.

25. Chalamwong Y, Mongkolsomlit S, Paitoonpong S, Ngaosri K, Thanadkah K, Prasomsup R, et al.
Attitude of native population (and concerned government agencies) towards migrant workers in Thailand in the context of Public Health, Economic Impact and National Security. Nonthaburi, Thailand: Health Systems Research Institute; 2018

26. Yang Z, Wang Y, Liu Z. Improving socially inclusive development in fast urbanized area: Investigate livelihoods of immigrants and nonimmigrants in Nansha Special Economic Zone in China. Habitat Int. 2019;86:10-8. 